\title{
Cultivation of College Students' Cultural Confidence Based on the Construction of Legal Culture in Colleges and Universities
}

\author{
Qinghua Zhang \\ Chifeng University \\ Chifeng, China 024000
}

\begin{abstract}
In terms of strengthening research on the construction of legal culture, from the perspective of the development of the theory itself, it is an important breakthrough and promotion in the research of legal theory and legal culture; from the perspective of implementing the strategy of ruling by law, it will provide for with a lasting spiritual impetus and profound cultural heritage; from the perspective of the cultivation of citizens' legal quality, it is an important link with fundamental and far-reaching influence; and from the perspective of promoting cultural confidence and implementing the strategy of powerful cultural country, it will greatly enrich and replenish the cultural connotation of socialist culture with Chinese characteristics. So, in the process of teaching, the colleges and universities shall strengthen the construction of legal culture and cultivate the cultural confidence of college students through establishing long-acting management mechanism for managing school by law, creating a strong atmosphere of construction of legal culture as well as paying attention to the positive factors in traditional culture and many other kinds of ways.
\end{abstract}

Keywords-legal culture; cultural confidence; college students

\section{INTRODUCTION}

On March 7, 2014, during the Guizhou delegation discussion of the second session of the 12th National People's Congress, Xi Jinping proposed to treat the "three confidence" and the cultural confidence as a whole for the first time. He said, "The core of a country's overall strength is cultural soft power, which is about the coherence of spirit, we shall continuously have confidence in our theory, path and political system, and we shall have confidence in our culture which is the most fundamental", 1which emphasizes that the "cultural confidence" is "the most fundamental". To strengthen the cultivation of the socialist legal culture with Chinese characteristics not only plays an important role in the construction of the state of law, but also is an important part of the construction of socialist culture with Chinese characteristics. To maintain cultural confidence, the legal culture is indispensable, and the legal culture confidence is its due content. Colleges and universities, as the institutions of higher education, bear the responsibility for the all-round cultivation of college students. They shall not only impart the professional skills of college students, but also cultivate qualified builders and successors for national and social development. The cultivation of ideological and cultural qualities, including cultural confidence, is an essential part of university education. Colleges and Universities should give full play to their main position of the ideological and political education function to cultivate new era college students with strong cultural confidence that meet the needs of social development through strengthening the construction of campus legal culture and actively creating rich campus legal culture atmosphere.

\section{THE NECESSITY AND PRACTICAL SigNIFICANCE OF THE CONSTRUCTION OF SOCIALIST LEGAL CULTURE WITH CHINESE CHARACTERISTICS}

To strengthen the research on the construction of legal culture is the need of practice and the inevitable response to the theoretical mission. Firstly, in the context of further promotion the strategy of ruling by law, it can fulfill the urgent need to solve the problem of the deep recessive legal culture obviously lagging behind the surficial dominant legal culture. Secondly, in the context of continuous promotion of the national legal education project, it can fulfill the urgent need to solve the problem of lack of motive power and selfcultivation of the citizens in the overall legal quality. Thirdly, in the context of promoting cultural confidence and implementing the strategy of cultural power, it can solve the urgent need to make up the short board of high quality legal culture so as to reverse the influence of the culture of the rule of man. Fourthly, in the background of innovation and prosperity of socialist jurisprudence with Chinese characteristics, it can fulfill the urgent need to solve the problem that the legal culture and legal theory research is not strong enough on the influence on the reality.

The practical necessity of the study of legal culture can naturally lead to the significance of the study of legal culture:

Firstly, from the perspective of the development of the theory itself, it is an important breakthrough and promotion in the research of legal theory and legal culture. The study of legal culture discussed here refers to a series of systematic and holistic studies on global issues that are represented by the concept of legal culture and the proposition of socialist legal culture with Chinese characteristics and that involve 
both the theoretical and practical aspects in recent years. It has its objective inevitability and significant and far-reaching significance that this research emerges in the current China and is now gradually being pushed from the academic front to the center of public opinion. Some scholars have indicated from the macro perspective of Chinese legal culture history in their articles that, "as a legal cultural form that transcends the concept of state rule of law and the concept of liberal rule of law, the concept of socialist rule of law that was formally proposed in 2006 represents the third wave of the centuryold legal culture in China, whose core value is fairness and justice and social harmony". 2 There is a very significant theoretical and practical significance in the ongoing deep research on the legal culture, which will take the new theoretical vitality and cultural influence to lead the socialist legal culture with Chinese characteristics to a brighter future and promote the research of jurisprudence and legal culture to a new level.

Secondly, from the perspective of the implementation of the strategy of ruling by law, it will provide a lasting spiritual impetus and profound cultural heritage. "The rule of law with full meaning includes three aspects: legal system, nomocracy system, legal culture". 3 In the current practice of rule of law in China, the construction of legal system and nomocracy system is basically complete, but the favorable legal culture is very scarce. The legal culture is not only the practical content and basic element of the legal construction and an important part of the establishment of a legal state, but also an important guarantee for the realization of a lawbased government and a law-based society, which provides spiritual impetus, intellectual support and cultural conditions for the legal construction. The study of the legal culture in China first appeared in the 1980s, but it has not attracted the attention of the academic circles. With the continuous advancement of the process of the rule of law in the new era, the underlying problem existing in the legal construction in China - the absence of the legal culture - seriously restricts the process of the construction of the law-based society, which arouses the reflection of academia and society. Since the new century, the academic circles have paid more and more attention to the legal culture, and in recent years, the study of the legal culture reached its peak.

Thirdly, from the perspective of the cultivation of citizens' legal quality, it is an important link with fundamental and far-reaching influence. As far back as 1997, the goal of ruling the country by law was first proposed at the 15th National Congress of the CPC, but up to this day, there are big problems in the legal awareness and the legal thinking among both the ordinary citizens and the functionaries of state organs, in the practice of rule of law, there appears many issues such as "show contempt for law", "difficult to observe the law", "the human relationship is bigger than the law" and so on. On the surface, the appearance of these issues appears to be caused by lax enforcement, however in essence, it is the consequence of lacking the necessary spiritual support of legal culture at the operational level. There is a statement in Mencius that, "the law itself is not sufficient for the governance", if there is no good legal culture as the support, even the perfect law cannot be effectively implemented. A good legal culture can enhance people's belief in the law, facilitate the law to be deeply rooted in the hearts of people, and enhance the initiative, enthusiasm and practical operating abilities of citizens to abide by the law and use the law, so that the law can be effectively implemented.

Fourthly, from the perspective of promoting cultural confidence and implementing the strategy of cultural power, it will greatly enrich and replenish the connotation of socialist culture with Chinese characteristics. In October 2014, Xi Jinping pointed out in the symposium on literature and art, "Culture is an important force for national survival and development. Every leap forward in human society and each time of sublimation of human civilization is accompanied by the historic progress of culture". Culture plays a vital role in the development and progress of a country or a nation, in the period of social transformation, if the culture does not change, the new system and law can hardly make a real difference. Therefore, in the new period, we should accelerate the process in replacing the traditional culture of rule of man with the socialist legal culture with Chinese characteristics, and realize the creative transformation and innovative development of traditional culture. As part of the socialist culture with Chinese characteristics, the socialist legal culture with Chinese characteristics not only affects the process of the legal construction, but is also closely related to the construction of socialist culture with Chinese characteristics. The establishment of a new socialist legal culture with Chinese characteristics will undoubtedly enrich and develop the connotation of socialist culture with Chinese characteristics.

\section{The CONSTRUCTION PATH OF LEGAL Culture IN COLLEGES AND UNIVERSITIES}

A long-acting management mechanism of administrating the school according to law shall be established. Firstly, the constitution and rules of the university shall be established. School constitution is the source and power of the school's sustainable development, further establishing and improving the constitution of higher education is the premise and foundation of legalization of colleges and universities as well as the scientific basis of "administrating the school according to law" in colleges and universities. The school constitution shall be enacted in accordance with the law and its relevant provisions. After enactment of the constitution, we shall formulate the development plan of colleges and universities and further refine the management system according to the fact of the school. We shall clarify the responsibility and improve the mechanism to ensure that the school constitution is implemented. The enactment of the rules and regulations of colleges and universities shall adhere to the four principles of legality, scientificity, democracy and procedural. Secondly, we shall improve the mechanism for democratic management and supervision, that is to say, we shall establish and improve the aid decision-making and advisory bodies both at school and college levels; comprehensively carry out the school affairs publicity work; further improve the faculty and staff congress system, and actively promote the construction of school democracy and improve 
democratic supervision. Thirdly, we shall establish and improve the campus democratic supervision mechanism to supervise the illegal and disciplinary actions of the managers, so as to protect the legal rights and interests of all the teachers and students to the maximum extent. Suggestion: Firstly, we shall establish an impeccable college legal supervision institution. We shall legalize various substantive supervision measures; improve the procedural mechanism and guarantee the procedural rights of teachers and students; set up various campus rights groups independently and give full play to the role of legal aid organizations by college students. Secondly, we shall expand channels for democratic supervision. To make the management of colleges and universities return to the core of academic research, we need to reconstruct the existing academic organization to expand its functions and fully mobilize the supervision enthusiasm of teachers and students. Thirdly, we shall establish the work system of reporting school administration to the faculty and staff congress to give full play to its supervision role. Fourthly, we shall innovate the communication mechanism and unblock channels of information. We shall implement school affairs publicity to make it convenient for all staff supervision.

We shall create a rich atmosphere of construction of legal culture. Firstly, we shall make full use of campus media to enhance the influence of the legal culture such as integrating the legal concept, laws and regulations into the vivid and image forms through school TV station, radio, microblog, etc. By using legal knowledge to deeply research and analyze social hot spots and difficult problems by means of case interpretation, we can make the teachers and students deeply understand the importance of the construction of legal culture and feel the majesty of the law, so as to enhance the influence and penetration of the legal culture. Secondly, we shall carry out legal education activities to improve students' legal quality. We can conduct legal concept training through the legal forum, case study, mock court and other forms. In the process of conducting mock courts, students can simulate judges, lawyers, prosecutors, defendants and other characters in person so as to better grasp some litigation procedures. The students can also simulate the trial of criminals, so that the students who are listening to them can receive education, so as to improve their consciousness of obeying the law. Thirdly, we shall host the popular forms of propagation to motivate the students to learn the law and use the law. Through the combination of simple legal knowledge imparting with legal practice teaching, the careful usage of each position and form and the comprehensive application of politics, literature, art, popularity, popularization, we can create a legal culture atmosphere with subtle humane and salutary influence to enable students to accept education and enlightenment in a subtle way. Fourthly, we shall organize legal knowledge competition activities, which can strengthen college students' acquisition of basic legal knowledge and basic legal principle, deepen their understanding of legal knowledge and theory and improve their legal quality. Fifthly, we shall organize students to attend the court to improve their legal practice ability. By organizing students to attend the court hearing, we can make the students well understand the society and improve their ability to solve practical problems by law. Sixthly, we shall employ legal experts to make reports to enhance students' academic thinking and let students understand the hot spots, difficulties, questions and development trends of the law studies and further strengthen the idea that law is greater than power.

We shall focus on seeking the positive factors in traditional culture. The traditional Chinese culture has a long history, although its core idea is "rule of man", which is substantially different from the modern "rule of law", however, there are some of its ideas which are of great referential significance to the construction of modern legal system, such as the Confucian idea of "rule of virtue", among which the political views of "rule by virtue and law", such as Confucius' idea of "governing by means of virtue", Mencius' idea of "benevolent governing", Xuncius' idea of "advocating rites and emphasizing law" as well as Dong Zhongshu's idea of "virtue primary and punishment secondary", all advocate the executive to implement the "rule of rite" which is to use morality to improve and govern the country and at the same time urge the ruler to be selfdisciplined and pay attention to the moral education of the people. For example, Confucius's people-oriented thought emphasizes that the people are the foundation of the country, and the destiny of the country and the monarch lies in the hand of people. All these ideas provide "local resources" and cultural legitimacy support for the construction of modern law. Although modern rule of law originated in the western countries, however, by digging out the positive elements of traditional Chinese culture in teaching and exploring local roots for the socialist legal culture with Chinese characteristics, we can cultivate students' confidence in legal culture.

\section{CONCLUSION}

College students' cultural confidence is a systematic concept, this paper aims to cultivate the cultural confidence of college students by strengthening the construction of legal culture in colleges and universities, which is a new attempt.

\section{REFERENCES}

[1] Xi Jinping Met With the Foreign Representative of the International Conference on "Learning about China" [N]. People's Daily, Nov. 04, 2015 (1).

[2] Yu Zhong. The Idea of Socialist Rule of Law: the Third Wave of the Century-old Legal Culture in China [J] Legal Forum, 2012, (1).

[3] Zhang Wenxian, the Cultural Connotation of the Rule of Law -- the Cultural Legal construction in China [J], Jilin University Journal Social Science, 2015 (4). 